\title{
Striving to Make Massage Therapy Accessible to Older Adults: an Interview with Niki Munk, PhD, LMT
}

\author{
Ann Blair Kennedy, LMT, BCTMB, DrPH, \\ Executive Editor, IJTMB \\ Department of Biomedical Sciences, Division of Behavioral, Social, and Population Health, \\ University of South Carolina School of Medicine Greenville, Greenville, SC, USA
}

First she became a licensed massage therapist in Kentucky. Then, in a quest to improve the care she provided to her elderly clinical population, Niki Munk continued her journey by furthering her education and receiving her doctorate in gerontology. Dr. Munk, a massage therapy researcher at Indiana University's IUPUI campus, shares in this interview her optimism on the future of the massage therapy profession and massage therapy research. Dr. Munk also provides insight into the way she makes decisions, and from whom she would like to receive advice.

She has a passion for finding ways to improve the life and health for those over the age of 65 , and it all began with her massage therapy practice. Dr. Niki Munk began her trip to her current profession by first completing her massage therapy education in 2002. She attended the Lexington Healing Arts Academy for her initial massage therapy education and, shortly after completing her clinical training, she opened her massage therapy practice. Within five years, her practice was filled mostly with older adults and she felt she needed more education to be able to treat them adequately. This led her to begin her doctoral training in gerontology which she completed in 2011. After working with the Department of Family and Community Medicine at the University of Kentucky on an $\mathrm{NIH}$-funded, real-world massage therapy for chronic low-back pain, she accepted her current position in 2013 as a tenure-track Assistant Professor of Health Sciences at Indiana University on the IUPUI campus. She is one of 13 international Fellows in the Australian Research Centre in Complementary and Integrative Medicine's (ARCCIM) International Complementary Medicine Research Leadership Program, a coinvestigator on the Veterans Affairs-sponsored study, Trial Outcomes for Massage: Caregiver-Assisted vs. Therapist-Treated (VA TOMCATT) study (https:// clinicaltrials.gov/ct2/show/NCT03100539), and a Massage Therapy Foundation Trustee. Dr. Munk's research explores real-world massage therapy for chronic low-back pain, trigger point self-care, massage for amputation-related sequelae, and the reporting and impact of massage-related case reports, among other projects. Among Dr. Munk's various academic duties, she is a core professor the School of Health and Human Sciences' doctoral program in Health and Rehabilitation Sciences.

\section{Please tell us about your massage therapy research and how you feel that it has impacted the field of massage therapy.}

My emerging massage research agenda has three primary and complementary aims: 1) establish research programs to i) build the real-world massage therapy evidence base for pain and related symptoms, and ii) design, test, and implement alternative accessibility approaches to massage therapy benefit; 2) establish collaborative partnerships with other health and medical researchers interested in integrative and complementary medicine across the life course; and 3 ) increase the massage field's involvement with the research process. Much of the work I have disseminated lately have all had a massage therapist focus in one way or another:

- real-world massage therapy for chronic low-back pain (which found massage therapy provided by community therapists was beneficial for most real-world, complicated chronic low-back pain patients, particularly those who were 50 and older ${ }^{(1-3)}$;

- massage related case reports ${ }^{(4-5)}$ (a way massage therapists contribute to research); and

- therapeutic massage and bodywork for those with amputation. ${ }^{(6)}$

I am very interested in and committed to the massage therapy field and individual practitioners becoming competent research consumers and contributing to, and having a voice in, the research endeavors that relate to and impact our field. I am very hopeful that my newest endeavor as the Massage and Myotherapy Fellow in the International Complementary Medicine Research Leadership Program through University of Technology Sydney's ARCCIM will prepare me to 
further impact the massage therapy field by building my leadership and collaborative research skills. I hope ultimately to contribute to the massage research endeavor by mentoring and training future massage practitioner researchers.

\section{How did you become interested in researching massage therapy?}

Practically by accident. I was always interested in what I understood research to be (reading books and commentaries on things that interested me), but I actually only learned what real research is when I began my doctoral training in gerontology 12 years ago. I began what became my research career as a way to learn about older adults and the aging process so I could better understand how massage therapy can or should be used for aging-related functional, physical, and cognitive decline.

I started my massage career in 2001 and by 2006, my massage practice focused on older adults specifically and I did not feel my foundation massage training prepared me enough to really understand the whats and the whys of massage for aging-related concerns. I wanted to know how age-related conditions like Parkinson's disease, Alzheimer's, and general functional decline begin, and the points at which massage therapy could affect mechanistic pathways or symptom expression and/or experience. What I quickly learned was that, while my doctoral training did teach me about the biopsychosocial aspects of aging, older adulthood, and the life course, the main educational focus of my doctorate was how to assess, design, conduct, analyze, and disseminate research. I had fully intended to help bring more massage to the older adult population by completing my doctorate, returning to full-time private practice, and sharing what I learned with other massage therapists by developing continuing education courses. What I realized during my doctoral training was that I could ultimately bring massage to more older adults in the long run by contributing to the massage therapy research enterprise, helping to develop massage's evidence base, and working to get massage therapy accessible through Medicare, which is the primary health care coverage in the US for people 65 and older.

\section{How do you integrate stakeholders (e.g., practicing massage therapists, massage patients/clients) into your research planning, implementation, and/or dissemination?}

In many ways. While I no longer have a private massage therapy practice, I stay connected to the field by keeping my license up-to-date, taking continuing educating classes, and talking with my massage colleagues about what is happening in the field and in practice (it is very easy to get wholly sucked into the academic environment). All of the trial research I have conducted to date has utilized practicing community massage therapists as intervention applicants and, in many cases, rely on them to develop the treatment plan for the research participant in an effort to reflect real-world massage therapy practice. At both the University of Kentucky and now Indiana University on the IUPUI campus, I have helped to develop and cultivate a cadre of community-practicing massage therapists for intervention delivery. In each case, massage therapist working with me on research projects have been compensated and I have sought ways to appropriately include them in result implication considerations and dissemination.

In addition, I try to stay active and engaged with various massage field associations though research dissemination, giving talks, volunteering, and attending meetings to hear what field leaders, educators, and therapists have to say and are thinking about.

\section{Where do you see the massage therapy profession and/or massage therapy research in the next five years?}

This is a tricky question to answer because I am an inherent optimist who is struggling right now with many items that I perceive to be huge barriers in our field with regard to the progression of the profession in general, research and science in general, and the intersection of the two. There are several things that I would love to point to as a hope for the massage field and massage research in the next five years, but both are in precarious places due to policies, politics, and reality; I'm not sure that reconciliation is on the horizon such that a five-year time frame consideration is manageable.

For instance, some of the strongest evidence for massage therapy is regarding massage benefit for pain. Those with the worst pain outcomes in the US are those who are the least able to access massage therapy due to the out-of-pocket cost. The reality is that, in order for massage therapy to be accessible to a majority of various pain populations, massage therapy treatments have to be covered by Medicaid, Medicare, population-specific coverage (such as the VA), and private insurance. In general, for that to universally occur, massage therapy has to be delivered within a health care services model and right now, that is not typical in our field for a multitude of reasons including the lack of nationally consistent, high-level education and credentialing for new and established massage therapists. That is not meant as a "hit" on the field, but rather as a realistic assessment and one that we as a profession have to "own" before real solutions and strategic planning can occur. Maybe there are efforts in the works to address these concerns; I don't know. What I do know is that any such efforts should be done with mutual respect and amicability, and with the altruistic intent that puts the good of the field, 
practitioners, and massage recipients above those of business, personal gain, pride, and politics.

On a more optimistic note though, I suspect that the massage research endeavor will grow in positive ways over the next five years despite the significant cuts in funding and general attacks on research, science, and health care. There are several early career massage-focused researchers beginning to make their mark on the field and many other established researchers with building research programs focusing on massage therapy. I am really optimistic that these efforts will be able to sustain the forward momentum of the massage therapy profession and research over the next five years while other potentially limiting aspects get themselves worked out.

\section{How do you make decisions?}

I am pragmatic in the way I make decisions, choosing to keep my grounding in reality and my emotion in check. When I have "big" emotion about something, I step back to honestly look at the situation from all sides and identify my prejudices and bias, so I can be accountable. I take in as much information as I can, assess applicable process and procedure rules and/or policies, reverse engineer process steps starting from the desired end point, and set timelines. I weigh decisions with my priorities which include the good and health of society, a strong and sustainable massage profession, my family's interests, and my career. I have two young daughters who aspire to be scientists and positive contributors to society. I seek to raise these children to be moral, truthful, and just. As a parent, I must model these characteristics in a transparent way which results in me talking to them a lot about why I do the things I do which, in turn, keeps me constantly thinking about these things and reinforcing my pragmatic ways. This, of course, applies to all avenues in which I make decisions - from my teaching philosophy, to my career, to the research questions I ask, to the methods I use to answer these questions, to how I provide service to the massage profession.

\section{If you were limited to just one person from whom to get advice and help, which person would you choose? Why?}

If I could, I would choose a future health and integrative medicine policy specialist, so they could advise me based on the "outcome" of all the things I have anxiety about with regard to health care, population health and policy, academia, research, and the massage profession. Since that really isn't an option, I will continue to cast my net wide for advice and help from a variety of people, including those who know better than-and think differently from-me!

\section{COPYRIGHT}

Published under the CreativeCommons AttributionNonCommercial-NoDerivs 3.0 License.

\section{REFERENCES}

1. Elder WG, Munk N, Love MM, Bruckner GG, Stewart KE, Pearce K. Real-world massage therapy produces meaningful effectiveness signal for primary care patients with chronic low back pain: results of a repeated measures cohort study. Pain Medicine. 2017;18(7):1394-1405.

2. Elder WG, Munk N. Using the Pragmatic-Explanatory Continuum Indicator Summary (PRECIS) model in clinical research: application to refine a Practice-based Research Network (PBRN) study. J Am Board Fam Med. 2014;27(6):846-854.

3. Munk N, Stewart K, Love MM, Carter E, Elder WG. Intersection of massage practice and research: community massage therapists as research personnel on an NIH-funded effectiveness study. Int J Ther Massage Bodywork. 2014;7(2):10-19.

4. Munk N, Boulanger K. Adaptation of the CARE Guidelines for therapeutic massage and bodywork publications: efforts to improve the impact of case reports. Int $J$ Ther Massage Bodywork. 2014;7(3):32-40.

5. Munk N, Shue S, Freeland E, Ralston RK, Boulanger K. Identifying inconsistencies and reporting deficits in therapeutic massage and bodywork (TMB) case reports authored by TMB practitioners: a TMB-adapted CAse REport (CARE) guidelines audit through 2014. Int J Ther Massage Bodywork. 2016;9(3):3-14.

6. Shue S, Richmond AK, Mulvihill T, Munk N. Treating individuals with amputations in therapeutic massage and bodywork practice: a qualitative study. Complement Ther Med. 2017;32:98-104.

Corresponding author: Ann Blair Kennedy, LMT, BCTMB, DrPH, University of South Carolina School of Medicine Greenville, 701 Grove Road, Greenville, SC 29605, USA

E-mail: Kenneda5@greenvillemed.sc.edu 